\title{
The Latin American Consortium of Studies in Obesity (LASO)
}

L. E. Bautista ${ }^{1}$, J. P. Casas², V. M. Herrera ${ }^{1}$, J. J. Miranda², P. Perel², R. Pichardo ${ }^{3}$, A. González $^{3}$, J. R. Sanchez ${ }^{4}$, C. Ferreccio ${ }^{5}$, X. Aguilera ${ }^{6}$, E. Silva ${ }^{7}$, M. Orósteguii, L. F. Gómez ${ }^{9}$, J. A. Chirinos ${ }^{10}$, J. Medina-Lezama ${ }^{11}$, C. M. Pérez ${ }^{12}$, E. Suárez ${ }^{12}$, A. P. Ortiz ${ }^{12}$, L. Rosero ${ }^{13}$, N. Schapochnik ${ }^{14}$, Z. Ortiz ${ }^{15}$ and D. Ferrante ${ }^{16}$, on behalf of the investigators of the Latin-American Consortium of Studies in Obesity (LASO)

${ }^{1}$ Department of Population Health Sciences, University of Wisconsin, Madison, WI, USA; '2Department of Epidemiology and Population Health, London School of Hygiene and Tropical Medicine, London, UK; ${ }^{3}$ Instituto Dominicano de Cardiología, Santo Domingo, República Dominicana; ${ }^{4}$ Centro Nacional de Alimentación y Nutrición, Instituto Nacional de Salud, Lima, Perú; ${ }^{5}$ Departamento de Salud Pública, Pontificia Universidad Católica de Chile, Santiago, Chile; ${ }^{6}$ Ministerio de Salud de Chile, Santiago, Chile; ${ }^{7}$ Instituto de Investigación y Estudios de Enfermedades Cardiovasculares, Facultad de Medicina, Universidad del Zulia, Maracaibo, Venezuela; ${ }^{8}$ Cardiovascular Diseases Epidemiologic Observatory, Epidemiologic Research Center, Universidad Industrial de Santander, Bucaramanga, Colombia; ${ }^{9}$ Health Division, Fundación FES Social, Bogotá, Colombia; ${ }^{10}$ Division of Cardiology, University of Pennsylvania School of Medicine and Philadelphia VA Medical Center, Philadelphia, PA, USA; ${ }^{11}$ Santa Maria Catholic University and Santa Maria Research Institute, Arequipa, Perú; ${ }^{12}$ Department of Biostatistics and Epidemiology, Graduate School of Public Health, Medical Sciences Campus, University of Puerto Rico, San Juan, Puerto Rico; ${ }^{13}$ Universidad de Costa Rica, Centro Centroamericano de Población, San José, Costa Rica; ${ }^{14}$ Ministerio de Salud de la Provincia de Tierra del Fuego, Ushuaia, Argentina; ${ }^{15}$ Instituto de Investigaciones Epidemiológicas Academia Nacional de Medicina, Buenos Aires, Argentina; ${ }^{16}$ Ministerio de Salud y Ambiente, Buenos Aires, Argentina

Received 8 December 2008; revised 23 February 2009; accepted 24 February 2009

Address for Correspondence: LE Bautista, Department of Population Health Sciences, University of Wisconsin-Madison, 610 Walnut Street, 703 WARF, Madison, WI 53726-2397, USA E-mail: lebautista@wisc.edu; JP Casas, Department of Epidemiology and Population Health, London School of Hygiene and Tropical Medicine, Keppel Street, London WC1E 7HT, UK. E-mail: Juan.Pablo-Casas@Ishtm.ac.uk

\section{Summary}

Current, high-quality data are needed to evaluate the health impact of the epidemic of obesity in Latin America. The Latin American Consortium of Studies of Obesity (LASO) has been established, with the objectives of (i) Accurately estimating the prevalence of obesity and its distribution by sociodemographic characteristics; (ii) Identifying ethnic, socioeconomic and behavioural determinants of obesity; (iii) Estimating the association between various anthropometric indicators or obesity and major cardiovascular risk factors and (iv) Quantifying the validity of standard definitions of the various indexes of obesity in Latin American population. To achieve these objectives, LASO makes use of individual data from existing studies. To date, the LASO consortium includes data from 11 studies from eight countries (Argentina, Chile, Colombia, Costa Rica, Dominican Republic, Peru, Puerto Rico and Venezuela), including a total of 32462 subjects. This article describes the overall organization of LASO, the individual studies involved and the overall strategy for data analysis. LASO will foster the development of collaborative obesity research among Latin American investigators. More important, results from LASO will be instrumental to inform health policies aiming to curtail the epidemic of obesity in the region.

Keywords: Consortium, health surveys, Latin America, obesity, risk factors.

obesity reviews (2009) 10, 364-370 


\section{Introduction}

The parallel processes of economic growth, migration and urbanization in Latin America have shaped the epidemiological transition by increasing life expectancy and modifying lifestyles (1-3). In fact, the increase in the consumption of high-energy-density foods and the reduction in the levels of physical activity have been recognized as the main factors associated with the accelerated epidemic of obesity in the region $(4,5)$. This epidemic is a matter of great concern because obesity constitutes a major modifiable risk factor for most of the leading causes of disability and mortality in Latin American countries, particularly cardiovascular diseases (CVD), diabetes mellitus, osteoarthritis and certain types of cancers $(6,7)$.

Although existing evidence suggests a parallel increment in total energy and fat consumption, the prevalence of sedentary behaviours and the prevalence of obesity (8-10), there are limited reliable data on the magnitude and consequences of the epidemic of obesity in the region. Furthermore, the association of behavioural and environmental factors with obesity, as well as the relationship between obesity and other chronic diseases, might be more complex in Latin America than in more homogeneous populations. In fact, the current definition of obesity, primarily derived from White populations from Europe and the United States (6), might not be optimal to identify individuals at high risk of CVD or of diabetes mellitus $(11,12)$.

Estimates of the prevalence of obesity have shown a great variability in Latin American populations, ranging from $9.9 \%$ to $35.7 \%$ (13). Women and individuals living in urban areas have been identified as the groups predominantly affected (14). In addition, obesity has been independently associated to low socioeconomic status and poorer educational level $(15,16)$, and contributes to the accentuation of health inequalities in the region (17). There is also evidence of a secular trend towards the increase in levels of obesity among the most economically developed Latin American countries during the past three decades $(14,18)$; however, similar data are not available for more disadvantaged populations. Moreover, most of the information on obesity has been obtained from nutritional surveys conducted during the first half of the nineties in adult women, mostly in urban settings, and little is known about adult men or the growing elderly population as well as rural obesity profiles.

In order to compose a comprehensive and updated picture of the impact of obesity in Latin America, we have established a multi-country consortium of obesity-related epidemiological studies conducted in the region. This initiative constitutes a strategy aimed to efficiently identify individual and population determinants of obesity, as well as to assess the role of obesity on the burden of CVD. We have chosen to focus on CVD for several reasons. First,
CVD is the leading cause of non-traumatic mortality in Latin America $(3,7)$; second, the projected burden of CVD will double during the following 20 years in the region $(19,20)$; and third, there is a well-established association between obesity and the incidence of major cardiovascular risk factors and clinical cardiovascular events (21).

The specific objectives of the Latin American Consortium of Studies in Obesity (LASO) are (i) To accurately estimate the prevalence of obesity and its distribution by sociodemographic characteristics in Latin America; (ii) To identify ethnic, socioeconomic and behavioural factors (nutritional and physical activity patterns) associated to the prevalence of obesity; (iii) To estimate the association between various anthropometric indicators of obesity and classic cardiovascular risk factors and (iv) To quantify the validity of standard definitions of obesity in this population. Along with the accomplishment of these objectives, it is expected that the consolidation of LASO will foster the development of collaborative, harmonized studies on the association between obesity and other relevant chronic diseases in the region. LASO will help understand the obesity epidemic and develop future studies to evaluate the determinants and the impact of obesity in Latin America.

The aim of this manuscript is to present the protocol for LASO, describe the use of standardized methodologies for the pooling of data from individual studies and provide a general description of participating studies and their methodologies.

\section{Materials and methodology}

\section{Identification and selection of studies}

Studies included in LASO are cross-sectional or prospective population-based cohort studies, based on random samples of well defined free-living population. All studies have individual data on demographic and socioeconomic indicators and anthropometric indicators of obesity collected through physical examination. Moreover, they have at least one of the following (i) Direct measurement of major cardiovascular risk factors; (ii) Determination of levels of physical activity and (iii) Determination of nutritional patterns. The search for potential participant studies is based on computer-assisted literature searches of health-related databases; hand-searching of obesity, cardiology, epidemiology and other relevant journals; and personal communications with cardiovascular and obesity researchers from the region.

\section{Ethical approval, informed consent and confidentiality of the data}

All studies have been approved by their respective local Institutional Review Board, and all participants provided 
their informed consent. The investigators of the original studies provide written consent for the use of their data before transferring and inclusion into the Consortium's central database at the University of Wisconsin at Madison. The data remain the property of the principal investigators of each participant study and are securely stored in studydedicated computers. The central database does not include codes or data that may directly or indirectly allow the identification of individuals participating in the original studies.

\section{Consortium management and coordination}

The LASO Steering Committee includes the principal investigators from all original studies. The tasks of this committee include (i) Coordinating the recruitment of new studies; (ii) Developing and prioritizing research questions to be addressed by the analysis of pooled data; (iii) Identifying and securing funds for the study; (iv) Producing and disseminating scientific reports of the ongoing research projects among members of the Consortium and (v) Acting as a publication committee. Parallel to the Steering Committee, a statistical centre has been constituted as an external academic instance responsible for the creation and management of the Consortium's central database, as well as for data analysis and generation of preliminary reports. This centre is based at the Department of Population Health Sciences, University of Wisconsin at Madison.

\section{Study variables}

Individual data collected in each study are categorized in five domains (Table 1) (i) Demographics, including age, gender, race or ethnic group; (ii) Indicators of socioeconomic status, including socioeconomic stratification, educational attainment, income, occupation and area of residency; (iii) Anthropometric indicators of total and regional obesity, measured by physical examination; (iv) Classic cardiovascular risk factors, including measurements of blood pressure and the laboratory assessment of glucose and lipid fractions and (v) Behavioural risk factors, including smoking status, alcohol consumption, physical activity and nutritional intake. Continuous variables such as anthropometric measures, blood pressure, glucose and lipid fractions are categorized according to current standard definitions. Whenever possible, categorical variables are recoded following standard procedures to maximize comparability among studies. Data on study-specific procedures are used to assess heterogeneity among studies.

\section{Data transfer and checking}

Password-protected data files are transferred from the individual studies to the Consortium's statistical centre using
Table 1 Variables available in the Latin American Consortium of Studies in Obesity (LASO)

\begin{tabular}{|c|c|}
\hline Domain & Variable (description) \\
\hline Demographic & $\begin{array}{l}\text { Age (years); gender (male/female) } \\
\text { Ethnicity (Amerindian/Black/White/other) }\end{array}$ \\
\hline Socioeconomic & $\begin{array}{l}\text { Educational attainment (highest level or total years) } \\
\text { Income (individual or household) } \\
\text { Occupation (occupational categories) } \\
\text { Area of residency (urban/rural) }\end{array}$ \\
\hline Anthropometry* & $\begin{array}{l}\text { Body weight }(\mathrm{kg}) / \text { height }(\mathrm{m}) \\
\text { Waist circumference }(\mathrm{cm}) \\
\text { Hip circumference }(\mathrm{cm})\end{array}$ \\
\hline $\begin{array}{l}\text { Cardiovascular } \\
\text { and metabolic } \\
\text { risk factors* }\end{array}$ & $\begin{array}{l}\text { Systolic/diastolic blood pressure }(\mathrm{mmHg}) \\
\text { Glucose }\left(\mathrm{mmol} \mathrm{L}{ }^{-1}\right) \\
\text { Total, HDL and } \mathrm{LDL} \text { cholesterol (mmol L-1) } \\
\text { Triglycerides }\left(\mathrm{mmol} \mathrm{L}^{-1}\right)\end{array}$ \\
\hline $\begin{array}{l}\text { Behavioural } \\
\text { risk factors }\end{array}$ & $\begin{array}{l}\text { Smoking status (never, past or current; cigarettes } \\
\text { per day) } \\
\text { Alcohol consumption (type of beverage, frequency } \\
\text { and quantity) } \\
\text { Physical activity (type of activity, frequency and } \\
\text { duration) } \\
\text { Foods/nutrients' intake (food frequency } \\
\text { questionnaires) }\end{array}$ \\
\hline
\end{tabular}

*Measured by physical examination or laboratory analysis. HDL, high-density lipoprotein; LDL, low-density lipoprotein.

electronic mailing. A codebook and a transference form containing a list of parameters directly estimated from the original datasets are included as part of the data transfer protocol. For security purposes, the datasets and accompanying files are encrypted before transferring using keywords known only to the coordinator of the Consortium and the principal investigators of each study. Specific parameters calculated from each study after data transfer are compared with those obtained by the study investigators before data transfer. In the case of inconsistencies, the data are back-transferred to ensure identical results are obtained with both datasets. The data are then converted to a standard format and incorporated to the Consortium's central database.

\section{Statistical analysis}

Specific data analysis strategies are used for each specific study using LASO data. However, some statistical procedures are applied for all analyses. We use multivariate imputation by chained equations to fill out missing values within studies in order to minimize selection bias because of missing data (22). Multiple imputed datasets are generated and the parameters of interest are averaged across datasets, using Rubin's formula (23). In addition, we use post-stratification by the age and gender distribution of the 
whole population in the countries included in the specific analysis as a way to minimize bias resulting from nonresponse and sampling frame under-coverage (24). Poststrata are constructed using the population totals by country, gender and age group (20-29, 30-39, 40-49, $50-59,60-69,70-79$ and 80 years and older). Population distribution data are obtained from the U.S. Census Bureau (http://www.census.gov) for Puerto Rico and from the Centro Latinoamericano y Caribeño de Demografía CELADE (http://www.cepal.org.ar/Celade) for all other countries.

Multiple weighted linear and logistic regression are implemented in order to (i) Compare the distribution of anthropometric indicators and the prevalence of obesity and cardiovascular risk factors in groups defined by demographic and socioeconomic characteristics; (ii) Predict the prevalence of total and regional obesity in these groups and (iii) Quantify the independent effect of total and regional obesity on the distribution of individual cardiovascular risk factors and coronary heart disease risk. In order to determine which anthropometric indicator of obesity better identifies individuals with specific cardiovascular risk factors or who are at high risk of coronary heart disease, we estimate and compare the areas under the receiver operator characteristic (ROC) curves using the method of placement values $(25,26)$. Finally, optimal cut-points for the anthropometric indicators of obesity are also determined on the basis of the ROC analysis by estimating the values of the indicator that minimize the cost of misclassifying individuals according to the presence of specific cardiovascular risk factors or the risk of coronary heart disease (27).

\section{Publication policy}

Manuscripts derived from the analysis of aggregated data undergo an internal peer-review process. Manuscripts cir- culate among the members of the Steering Committee, who provide comments and generate a feedback report to the main authors. The main author addresses and responds to the comments and prepares a final revised version. LASO's Steering Committee approves the final manuscript before submission. Finally, as part of a strategy of communication and recruitment, the Consortium has developed a website (http://www.pophealth.wisc.edu/laso), which contains general information on the participant studies, the principal investigators and their groups, and links to the all the publications derived from the analysis of pooled data.

\section{Results}

Eleven studies (28-38) from eight countries in Latin America and the Caribbean (Argentina, Chile, Colombia, Costa Rica, Dominican Republic, Peru, Puerto Rico and Venezuela) are currently included in the LASO, including a total of 32462 subjects (Table 2). The overall mean age is 45.8 years (standard deviation 18.6 years; range: 15-109 years) and the male proportion is $40.6 \%$, ranging from $31.0 \%$ to $50 \%$. Four studies are national health surveys $(29,32-34)$, but one of them is restricted to urban population (33). In addition, one study was conducted at the state level (38), five exclusively targeted urban populations from single cities $(28,30,31,36,37)$ and other sampled an urban and a rural population (35).

Data on demographic and socioeconomic characteristics, smoking, medical history and current treatment of hypertension and diabetes were collected by trained interviewers using similar questionnaires (available to the members of the statistical centre) in all studies. Standing height and weight were measured in all surveys with the participants wearing light clothing and no shoes. Waist circumference was measured at the umbilical level in five studies $(28,31,32,36,38)$, at the midpoint between the lowest rib and the iliac crest in four studies $(29,30,34,35)$, at the high

Table 2 Characteristics of the studies from the Latin American Consortium of Studies in Obesity (LASO)

\begin{tabular}{|c|c|c|c|c|c|c|}
\hline Study & Location & Year & Target & Sample & Age & Male \\
\hline Encuesta de Factores de Riesgo (28) & Argentina, Ushuaia/Rio Grande & 2003-2004 & City & 1135 & $18-65$ & $48 \%$ \\
\hline Encuesta Nacional de Salud (29) & Chile & 2003 & National & 3619 & $16-97$ & $45 \%$ \\
\hline CARMEN (30) & Colombia, Bogotá & 2001 & City & 2962 & $15-69$ & $43 \%$ \\
\hline CARMEN (31) & Colombia, Bucaramanga & 2001 & City & 2994 & $15-66$ & $36 \%$ \\
\hline CRELES (32) & Costa Rica & 2004-2006 & National & 2826 & $60-109$ & $46 \%$ \\
\hline EFRICARD (33) & Dominican Republic & 1998 & National (urban) & 6184 & $18-75$ & $34 \%$ \\
\hline ENINBSC-ECNT (34) & Peru & 2005 & National & 4209 & 20-95 & $50 \%$ \\
\hline PERU MIGRANT (35) & Peru, Lima/Ayacucho & 2007-2008 & Urban/rural & 990 & 29-92 & $47 \%$ \\
\hline PREVENCION (36) & Peru, Arequipa & 2004-2006 & City & 1878 & $20-80$ & $46 \%$ \\
\hline Metabolic syndrome in San Juan (37) & Puerto Rico & 2005-2007 & City & 865 & $21-79$ & $35 \%$ \\
\hline The Zulia CHD Factor Study (38) & Venezuela, Zulia & 1999-2001 & State & 4800 & 20-97 & $31 \%$ \\
\hline
\end{tabular}

$\mathrm{CHD}$, coronary heart disease. 
point of the iliac crest in one study (37), and was not measured in one study (33). Hip circumference was measured at the maximum extension of the buttocks. Blood pressure measurements were conducted at least twice in all but one study (34), following standard recommendations (39). Blood samples were obtained in all studies after $\geq 8 \mathrm{~h}$ of fast. Blood glucose, total cholesterol and high-density lipoprotein cholesterol were measured enzymatically by automated methods. Low-density lipoprotein (LDL) cholesterol was directly measured in two studies $(36,38)$ and was calculated using the Friedewald equation (40) otherwise.

For effects of statistical analyses, hypertension is defined as a systolic blood pressure $\geq 140 \mathrm{mmHg}$, or as a diastolic blood pressure $\geq 90 \mathrm{~mm} \mathrm{Hg}$, or as current antihypertensive treatment, and participants are considered diabetics if their fasting glucose is $\geq 7.0 \mathrm{mmol} \mathrm{L}^{-1}$ $\left(126 \mathrm{mg} \mathrm{dL}^{-1}\right)$ or if they report current pharmacological treatment for diabetes (either insulin or oral agents). High total cholesterol is defined as a total cholesterol $\geq 6.15 \mathrm{mmol} \mathrm{L}^{-1}\left(240 \mathrm{mg} \mathrm{dL}^{-1}\right)$. High LDL cholesterol and low high-density lipoprotein cholesterol are deemed present if the corresponding cholesterol levels are $\geq 4.10$ $\left(160 \mathrm{mg} \mathrm{dL}^{-1}\right)$ and $<1.03 \mathrm{mmol} \mathrm{L}^{-1}\left(<40 \mathrm{mg} \mathrm{dL}^{-1}\right)$, respectively. Hypertriglyceridemia is defined as a level of triglycerides $\geq 2.25 \mathrm{mmol} \mathrm{L}^{-1}\left(200 \mathrm{mg} \mathrm{dL}^{-1}\right)$. Also, participants are classified as current smokers if they report to have smoked at least 100 cigarettes in their lives and have smoked during the previous 1-6 months in two studies $(30,35)$ or if they were smoking at least one cigarette per day at the moment of the evaluation in the remaining studies. Overall obesity is defined as body mass index $\geq 30 \mathrm{~kg} \mathrm{~m}^{-2}$ and abdominal obesity as a waist circumference $\geq 88 \mathrm{~cm}$ in women and $\geq 102 \mathrm{~cm}$ in men, following the recommendations of the World Health Organization (6).

Finally, as a strategy to summarize the cardiovascular risk, the expected 10-year risk of coronary heart disease is estimated in men and women 30-74 years old by using the Framingham equation (41). Considering that the equation may overestimate the absolute risk of coronary heart disease (CHD) in Latin Americans (42), we use the population-specific mean values for the risk factors in order to minimize such effect. Participants with an estimated 10 -year risk of $\mathrm{CHD} \geq 20 \%$ are considered at 'high risk', because current standards of care recommend aggressive risk reduction and selective use of proven drug therapies in these individuals $(43,44)$.

\section{Conclusion}

The LASO constitutes a multinational initiative to effciently assess the public health problem of obesity, its sociodemographic and behavioural determinants, and its impact on the risk of CVD in the region. The strategy of combining data captured at individual level from population-based studies will allow not only to increase precision in estimating the prevalence of obesity, but also to capture the heterogeneity of the effect of this condition on the health of the Latin American population. Finally, the Consortium, which currently includes data from 11 studies involving approximately 33000 participants, will serve as framework for the interchange of observational data, discussion and interpretation of regional epidemiological evidence, and ultimately the formulation of high-quality, standardized, collaborative proposals on obesity and other prevalent chronic diseases.

\section{Conflict of Interest Statement}

None.

\section{Acknowledgements}

The authors want to express their thanks to Dr Paula Margozzini (Pontificia Universidad Católica de Chile, Chile), Claudia González (Ministerio de Salud, Chile), Dr Luis A. Santa María (Instituto Nacional de Salud, Perú), Dr Manuel Guzmán and Dr Lillian Haddock (University of Puerto Rico, School of Medicine, Puerto Rico), and Professors José Villasmil and Mairelis Nuváez (Universidad del Zulia).

The 'Prueba de Validación de la Encuesta Nacional de Factores de Riesgo' was funded by the Ministerio de Salud de la República Argentina and the Gobierno de la Provincia de Tierra del Fuego, Antártida e Islas del Atlántico Sur, Argentina. The 'Encuesta Nacional de Factores de Riesgo' was funded by the Ministerio de Salud de la República Argentina. The 'Encuesta Nacional de Salud 2003' was funded by the Ministerio de Salud, Chile. The 'Estudio CARMEN Santa Fe' was funded by the Secretaría Distrital de Salud de Bogotá, Colombia. CARMEN-Bucaramanga was funded by the Secretaría de Salud Municipal de Bucaramanga and the Secretaría Departamental de Salud de Santander, Colombia. The 'Costa Rica: Estudio de Longevidad y Envejecimeinto Saludable (CRELES)' was funded by The Wellcome Trust Foundation, grant number 072406. The 'Estudio de Factores de Riesgo Cardiovascular en la República Dominicana (EFRICARD)' was funded by the Sociedad Dominicana de Cardiología, Brystol Myers Squibb, Warners Lambert (Pfizer), Novartis, Merck Sharp Dohme and Magnachen International. The 'Encuesta Nacional de Indicadores Nutricionales, Bioquímicos, Socioeconómicos y Culturales Relacionados con las Enfermedades Crónico Degenerativas (ENINBSC-ECNT)' was funded by the Instituto Nacional de Salud, Lima, Perú. JJM and the 'PERU MIGRANT study' were supported by a Wellcome Trust Research Training Fellowship (GR074833MA). The study 'Prevalencia de Enfermedades 
Cardiovasculares y Factores de Riesgo Coronario en Arequipa (PREVENCION)' was partially supported by the Instituto de Investigación Santa Maria. The study of the 'Prevalence of Metabolic Syndrome and its Individual Components in the adult population of the San Juan Metropolitan Area in Puerto Rico' was funded by an unrestricted grant from Merck Sharp \& Dohme Corporation with additional support from the National Institutes of Health/National Center for Research Resources (NCRR/ NIH) grant awards G12RR03051 and P20RR011126. The Zulia Coronary Heart Disease Risk Factor Study was funded by the Fondo Nacional de Ciencia, Tecnología e Innovación (FONACIT) and the Fundación Venezolana de Hipertensión Arterial (FUNDAHIPERTENSION).

\section{References}

1. Uauy R, Monteiro CA. The challenge of improving food and nutrition in Latin America. Food Nutr Bull 2004; 25: 175-182. 2. Pratt M, Jacoby ER, Neiman A. Promoting physical activity in the Americas. Food Nutr Bull 2004; 25: 183-193.

3. Perel P, Casas JP, Ortiz Z, Miranda JJ. Noncommunicable diseases and injuries in Latin America and the Caribbean: time for action. PLoS Med 2006; 3: e344.

4. Pena M, Bacallao J. Obesity and its patterns in the region. Rev Panam Salud Publica 2001; 10: 75-78.

5. Popkin BM. The shift in stages of the nutrition transition in the developing world differs from past experiences! Public Health Nutr 2002; 5: 205-214.

6. World Health Organization. Obesity: Preventing and Managing the Global Epidemic. Report of A WHO Consultation on Obesity. WHO: Geneva, 1997.

7. World Health Organization. The World Health Report, 2002: Reducing Risks, Promoting Healthy Life. WHO: Geneva, 2002.

8. Rivera JA, Barquera S, Campirano F, Campos I, Safdie M, Tovar V. Epidemiological and nutritional transition in Mexico: rapid increase of non-communicable chronic diseases and obesity. Public Health Nutr 2002; 5: 113-122.

9. Albala C, Vio F, Kain J, Uauy R. Nutrition transition in Chile: determinants and consequences. Public Health Nutr 2002; 5: 123 128.

10. Kain J, Vio F, Albala C. Obesity trends and determinant factors in Latin America. Cad Saude Publica 2003; 19(Suppl. 1): S77-S86.

11. Sanchez-Castillo CP, Velazquez-Monroy O, Berber A, LaraEsqueda A, Tapia-Conyer R, James WP, Encuesta Nacional de Salud (ENSA) 2002 Working Group. Anthropometric cutoff points for predicting chronic diseases in the Mexican National Health Survey 2000. Obes Res 2003; 11: 442-451.

12. Pitanga FJ, Lessa I. Waist-to-height ratio as a coronary risk predictor among adults. Rev Assoc Med Bras 2006; 52: 157-161. 13. Filozof C, Gonzalez C, Sereday M, Mazza C, Braguinsky J. Obesity prevalence and trends in Latin-American countries. Obes Rev 2001; 2: 99-106.

14. Monteiro CA, D’A Benicio MH, Conde WL, Popkin BM. Shifting obesity trends in Brazil. Eur J Clin Nutr 2000; 54: 342 346.

15. Martorell R, Khan LK, Hughes ML, Grummer-Strawn LM. Obesity in Latin American women and children. J Nutr 1998; 128: 1464-1473.
16. Monteiro CA, Moura EC, Conde WL, Popkin BM. Socioeconomic status and obesity in adult populations of developing countries: a review. Bull World Health Organ 2004; 82: 940-946.

17. Monteiro CA, Conde WL, Lu B, Popkin BM. Obesity and inequities in health in the developing world. Int J Obes Relat Metab Disord 2004; 28: 1181-1186.

18. Williams K, Stern MP, Gonzalez-Villalpando C. Secular trends in obesity in Mexico City and in San Antonio. Nutr Rev 2004; 62: S158-S162.

19. Yusuf S, Reddy S, Ounpuu S, Anand S. Global burden of cardiovascular diseases: part I: general considerations, the epidemiologic transition, risk factors, and impact of urbanization. Circulation 2001; 104: 2746-2753.

20. Lanas F, Avezum A, Bautista LE, Diaz R, Luna M, Islam S, Yusuf S, INTERHEART Investigators in Latin America. Risk factors for acute myocardial infarction in Latin America: the INTERHEART Latin American Study. Circulation 2007; 115: 1067-1074.

21. Wilson PW, D’Agostino RB, Sullivan L, Parise H, Kannel WB. Overweight and obesity as determinants of cardiovascular risk: the Framingham experience. Arch Intern Med 2002; 162: 1867-1872. 22. van Buuren S, Boshuizen HC, Knook DL. Multiple imputation of missing blood pressure covariates in survival analysis. Stat Med 1999; 18: 681-694.

23. Rubin DB. Multiple Imputation for Nonresponse in Surveys. John Wiley \& Sons: New York, 1987.

24. Korn EL, Graubard BI. Analysis of Health Surveys. John Wiley \& Sons: New York, 1999.

25. Pepe MS, Cai T. The analysis of placement values for evaluating discriminatory measures. Biometrics 2004; 60: 528-535.

26. Dodd LE, Pepe MS. Partial AUC estimation and regression. Biometrics 2003; 59: 614-623.

27. Greiner M, Pfeiffer D, Smith RD. Principles and practical application of the receiver-operating characteristic analysis for diagnostic tests. Prev Vet Med 2000; 45: 23-41.

28. CEDES-Programa VIGI+A-Banco Mundial. In: Encuesta de Factores de Riesgo: Adaptación y Validación del Cuestionario Propuesto por OPS Para la Vigilancia Epidemiológica de los Factores de Riesgo. CEDES: Argentina, 2004, pp. 2003-2004.

29. Ministerio de Salud de Chile PUCdC. Encuesta Nacional de Salud Chile 2003. Ministerio de Salud: Santiago, Chile, 2003.

30. Gómez LF, Samper B, Espinosa G, Mateus JG, Gómez LC. Factores de riesgo cardiovascular en la localidad de Santa Fe de la ciudad de Bogotá. Resultados obtenidos en el área demostrativa Carmen. Boletín Epidemiológico Distrital 2004; 9: 4-12.

31. Bautista LE, Orostegui M, Vera LM, Prada GE, Orozco LC, Herran OF. Prevalence and impact of cardiovascular risk factors in Bucaramaga, Colombia: results from the Countrywide Integrated Noncommunicable Disease Intervention Programme (CINDI/ CARMEN) baseline survey. Eur J Cardiovasc Prev Rehabil 2006; 13: 769-775.

32. Méndez E, Rosero-Bixby L, Fernández X, Barrantes K. Comparación de los resultados de pruebas de laboratorio seleccionadas de un estudio poblacional de adultos mayores de Costa Rica. Población y Salud en Mesoamérica [serial online] 2007; 5: 2-15. 33. Pichardo R. Estudio de factores de riesgo cardiovascular en la República Dominicana (EFRICARD) 1996-1998. Archivos Dominicanos de Cardiología 1998;2: 3.

34. Ministerio de Salud. Encuesta Nacional de Indicadores Nutricionales, Bioquímicos, Socioeconómicos y Culturales relacionados con las Enfermedades Crónicas Degenerativas. Perú: 2006 (Unpublished report).

35. Miranda JJ. The Effect on Cardiovascular Risk Factors of Migration from Rural to Urban Areas in Peru - Study Protocol. 
[MSc Epidemiology]. London School of Hygiene and Tropical Medicine, University of London: London, 2005.

36. Medina-Lezama J, Zea-Diaz H, Morey-Vargas OL, BolanosSalazar JF, Munoz-Atahualpa E, Postigo-MacDowall M, CorralesMedina F, Valdivia-Ascuna Z, Cuba-Bustinza C, Paredes-Diaz S, Villalobos-Tapia P, Chirinos-Pacheco J, Goldberg RB, Chirinos JA. Prevalence of the metabolic syndrome in Peruvian Andean Hispanics: the PREVENCION Study. Diabetes Res Clin Pract 2007; 78: 270-281.

37. Perez CM, Guzman M, Ortiz AP, Estrella M, Valle Y, Perez N, Haddock L, Suárez E. Prevalence of metabolic syndrome in San Juan, Puerto Rico. Ethn Dis 2008; 18: 434-441.

38. Florez H, Silva E, Fernandez V, Ryder E, Sulbaran T, Campos G, Calmon G, Clavel E, Castillo-Florez S, Goldberg R. Prevalence and risk factors associated with the metabolic syndrome and dyslipidemia in White, Black, Amerindian and mixed Hispanics in Zulia State, Venezuela. Diabetes Res Clin Pract 2005; 69: 6377.

39. Frohlich ED, Grim C, Labarthe DR, Maxwell MH, Perloff D, Weidman WH. Recommendations for human blood pressure determination by sphygmomanometers: report of a special task force appointed by the steering committee, American Heart Association. Hypertension 1988; 11: 209A-222A.
40. Friedewald WT, Levy RI, Fredrickson DS. Estimation of the concentration of low-density lipoprotein cholesterol in plasma, without use of the preparative ultracentrifuge. Clin Chem 1972; 18: 499-502.

41. Wilson PW, D'Agostino RB, Levy D, Belanger AM, Silbershatz H, Kannel WB. Prediction of coronary heart disease using risk factor categories. Circulation 1998; 97: 1837-1847.

42. D'Agostino RB Sr, Grundy S, Sullivan LM, Wilson P, CHD Risk Prediction Group. Validation of the Framingham coronary heart disease prediction scores: results of a multiple ethnic groups investigation. [see comment]. JAMA 2001; 286: 180-187.

43. Wood D, De Backer G, Faergeman O, Graham I, Mancia G, Pyorala K. Prevention of coronary heart disease in clinical practice: recommendations of the second joint task force of European and other societies on coronary prevention. Atherosclerosis 1998; 140: 199-270.

44. National Cholesterol Education Program (NCEP) Expert Panel on Detection, Evaluation, and Treatment of High Blood Cholesterol in Adults (Adult Treatment Panel III). Third report of the National Cholesterol Education Program (NCEP) expert panel on detection, evaluation, and treatment of high blood cholesterol in adults (adult treatment panel III) final report. Circulation 2002; 106: $3143-3421$. 
Copyright of Obesity Reviews is the property of Blackwell Publishing Limited and its content may not be copied or emailed to multiple sites or posted to a listserv without the copyright holder's express written permission. However, users may print, download, or email articles for individual use. 